\title{
Kink of a Nasogastric Tube in the Bronchial System without Complications
}

\author{
Ji Hye Lee Yang Deok Lee Dong Jib Na \\ Department of Internal Medicine, Eulji University Hospital, Daejeon, Korea
}

A 84-year-old man, who had been diagnosed with and had received radiotherapy for esophageal cancer with lung metastasis 1 year previously, presented at our institution with a 1-month history of progressive dyspnea, cough and sputum. The patient's physical examination was unremarkable, with the exception of coarse breathing in both lower lung fields. The patient's arterial blood gas was analyzed at the time of presentation and found to be $\mathrm{pH}$ 7.46, with $\mathrm{PaCO}_{2}$ levels of $23 \mathrm{~mm} \mathrm{Hg}, \mathrm{PaO}_{2}$ levels of $50 \mathrm{~mm}$ $\mathrm{Hg}, \mathrm{HCO}_{3}{ }^{-}$levels of $16.4 \mathrm{mmol} / \mathrm{l}$, and $\mathrm{SaO}_{2}$ levels of $87 \%$. The patient's laboratory findings were normal, aside from an elevated leukocyte count $(13,010 / \mu \mathrm{l})$, C-reactive protein level $(19.27 \mathrm{mg} / \mathrm{dl})$ and LDH level (595 IU/l). A chest radiograph was abnormal, revealing widening of the upper mediastinum, blunting of the right costophrenic angle and consolidation of the right lower lung field. Based on these findings, we administered antibiotic therapy for pneumonia and recommended conservative management of dyspnea (including $\mathrm{O}_{2}$ supplement and bronchodilator therapy). The patient was supplied with 5 liters of $\mathrm{O}_{2}$ via a mask and a nasogastric tube was inserted to provide nutrients. Several hours later, the patient's dyspnea gradually improved.

On a follow-up chest radiograph, a line was made out which happened to be the radioopaque marker of the incorrectly placed nasogastric tube (fig. 1). Despite the kink of the nasogastric tube in the respiratory tract, the physician did not feel any resistance while advancing the tube and the patient did not cough or complain of dyspnea or chest tightness. The doctor auscultated the borborygmus over the epigastrium after insufflating air through the tube using a catheter-tip syringe.

A variety of methods have been used to confirm the proper placement of nasogastric tubes, such as monitoring the patient for signs of coughing and choking, auscultation of air insufflated through the tube, or fluid aspiration. In addition, the $\mathrm{pH}$ of aspirate can be tested and radiologic analysis can verify proper placement of the tube [1].

However, the absence of coughing and choking can be misleading, as decreased patient perception and impaired airway defenses can interfere with the signs of respiratory tube misplacement. Auscultation is a more commonly used method of monitoring tube placement; however, a tube that has inadvertently been

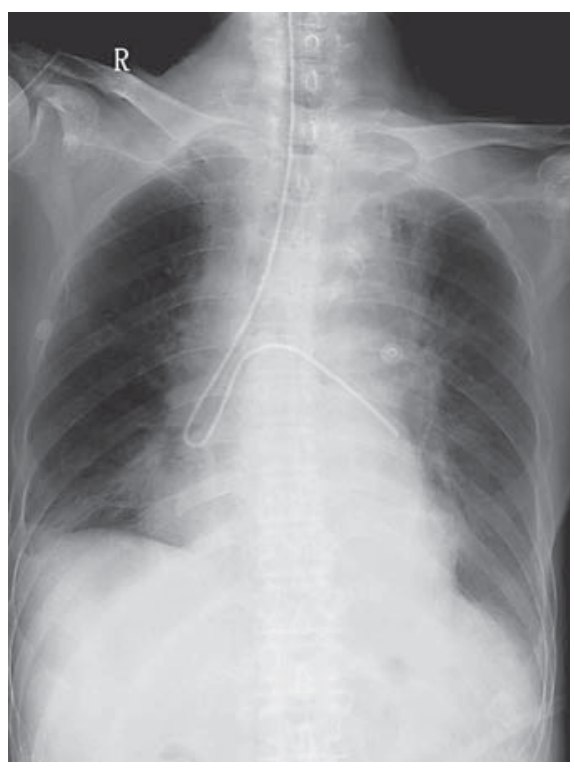

Fig. 1. Chest radiography revealing a kink of a misplaced nasogastric tube in the right main bronchus extending into the left main bronchus.

placed in the respiratory tract or esophagus can transmit a sound that is similar to that of air entering the stomach. Thus, radiography is the best method of confirming tube placement in patients who experience a decreased level of consciousness or neurological debilitation, in which case gag and cough reflexes may be suppressed.

Reference

1 Thomsen TW, Shaffer RW, Setnik GS: Videos in clinical medicine. Nasogastric intubation. N Engl J Med 2006;354:e16-e17.

\section{KARGER}

Fax +41613061234 E-Mail karger@karger.ch www.karger.com
(C) 2008 S. Karger AG, Base

0025-7931/10/0795-0420\$26.00/0

Accessible online at:

www.karger.com/res
Yang Deok Lee

Department of Internal Medicine, Eulji University Hospital

Eulji University School of Medicine, 1306 Dunsan-Dong Seo-Gu

302-799 Daejeon (Republic of Korea)

Tel. +82 42611 3153, Fax +82 42259 1111, E-Mail lydmd@hanmail.net 